\title{
WORLD HEALTH ORGANIZATION DRUG PRESCRIBING INDICATORS AT A UNIVERSITY PRIMARY HEALTH-CARE CENTER IN OMAN
}

\author{
AL-RUBKHI SS ${ }^{1}$, AL-HINAI $M^{2}$, AL-GHAFRI F ${ }^{3}$, AL BALUSHI KA ${ }^{4 *}$ \\ ${ }^{1}$ College of Medicine and Health Sciences, Sultan Qaboos University, Muscat, Oman. ${ }^{2}$ Department of Family Medicine and Public Health, \\ Sultan Qaboos University Hospital, Muscat, Oman. ${ }^{3}$ Department of Pathology, Sultan Qaboos University, Muscat, Oman. ${ }^{4}$ Department of \\ Pharmacology and Clinical Pharmacy, Sultan Qaboos University, Muscat, Oman. Email: mme51@squ.edu.om
}

Received: 02 September 2019, Revised and Accepted: 04 November 2019

ABSTRACT

Objective: This study aimed at evaluating the prescribing patterns of drugs based on the World Health Organization (WHO) indicators at the primary health-care Family Medicine and Community Health Clinic in Sultan Qaboos University Hospital, Oman.

Methods: This was a retrospective cross-sectional study covering a 6-month period in 2016 (January-June) for all patients attended Family Medicine and Community Health Clinic in Sultan Qaboos University Hospital, Oman. Data of 300 patients with 892 prescriptions were assessed during the study period.

Results: The average number of drugs per encounter (2.82), the percentage of encounters with antibiotics (13.3\%), and the percentage of encounters with an injection (7.6\%) were within the optimal range set by the WHO. The percentage of drugs prescribed by generic name (80.1\%) and the percentage of drugs prescribed from an essential drug list (EDL) (40.4\%) did not reach the optimal 100\% value set by the WHO.

Conclusion: Most of the WHO core prescribing indicators in the study were within the optimal range. Prescribing from the WHO EDL was suboptimal. These data will set ground to optimize rational drug prescribing in the primary health-care setting.

Keywords: Rational, Prescribing pattern, Prescribing indicators.

(c) 2020 The Authors. Published by Innovare Academic Sciences Pvt Ltd. This is an open access article under the CC BY license (http://creativecommons. org/licenses/by/4. 0/) DOI: http://dx.doi.org/10.22159/ajpcr.2020.v13i1.35567

\section{INTRODUCTION}

Drug prescribing quality plays a crucial role in treating health conditions monitored by health professionals. According to the World Health Organization (WHO), around 50\% of medications are prescribed inappropriately, which has consequences on patients' morbidity and mortality $[1,2]$. The WHO describes the rational use of medications as "patients receive medications appropriate to their clinical needs, in doses that meet their own individual requirements, for an adequate period of time, and at the lowest cost to them and their community" [3]. Irrational use of drugs has several consequences including ineffective treatment, adverse drug reactions, exacerbation of diseases, and the development of serious health conditions [4]. There are several causes for this irrational use of drugs, including polypharmacy, inappropriate use of antibiotics, overuse or underuse of drugs, indiscriminate use of injectable drugs, the use of costly drugs, and prescribing medicines that contravene clinical guidelines [5].

The WHO developed a set of core drug use indicators that are useful for studying patterns of drug prescribing in health-care facilities [6]. These are the number of drugs per encounter, the percentage of drugs prescribed by generic name, the percentage of antibiotics and injectable drugs per encounter, and the percentage of drugs prescribed from an essential drug list (EDL). These quantitative indicators are widely accepted as a global standard for identifying problems related to drug prescribing that may affect patient care.

The primary aim of this study was to evaluate the prescribing patterns of medications based on the WHO indicators at the primary health-care Family Medicine and Community Health Clinic at Sultan Qaboos University Hospital, Oman. The findings of the study will aid health-care providers and policy-makers to identify drug prescribing-related problem and initiate programs for rational drug prescribing.

\section{METHODS}

Study setting

The study was conducted in the Family Medicine and Community Health Clinic at Sultan Qaboos University Hospital, a primary care outpatient clinic in the Sultanate of Oman that provides free health-care services to all university employees and their dependents. The ethical approval was obtained from the Medical Research Ethics Committee at Sultan Qaboos University, Oman.

\section{Study design}

This was a retrospective cross-sectional study covering a 6-month period in 2016 (January-June) for all patients attended the Family Medicine and Community Health Clinic at Sultan Qaboos University Hospital. The patients' encounters that were included in this study were general illness encounters in all age groups and encounters for new outpatients attending for curative treatment, representing a mix of health problems. The dermatology clinic is part of the Family Medicine and Community Health Clinic to which certain dermatological cases are referred. Patients coming only to collect their results, antenatal patients, prenatal care, and patients coming for immunization were excluded from the study. The electronic hospital information system program called "Trakcare" was used to extract relevant patients' information.

\section{Data collection}

The following patients' data were collected:

- Baseline data of the patients: Number of hospital registry, sex, age, body mass index, diagnosis, and patient's clinical outcome

- Drug prescription data: Number of drugs prescribed during the visit, class/name of drugs prescribed during the visit, route of administration, dosage, and duration

- The WHO core prescribing indicators. 
Table 1: The most common drugs prescribed for patients in Family Medicine and Community Health Clinic at Sultan Qaboos University Hospital ( $n=892$ prescriptions)

\begin{tabular}{ll}
\hline Drug name & Frequency (\%) \\
\hline Paracetamol & $68(7.6)$ \\
Diclofenac & $35(3.9)$ \\
Metformin & $28(3.1)$ \\
Esomeprazole & $26(2.9)$ \\
Aspirin & $26(2.9)$ \\
Rosuvastatin & $23(2.6)$ \\
Atorvastatin & $21(2.4)$ \\
Loratadine & $19(2.1)$ \\
Amlodipine & $18(2.0)$ \\
Gliclazide & $17(1.9)$ \\
\hline
\end{tabular}

Table 2: WHO core prescribing indicators at the Family Medicine and Community Health Clinic in Sultan Qaboos University Hospital

\begin{tabular}{lll}
\hline Prescribing indicator & Average/Percent & Optimal values \\
\hline $\begin{array}{l}\text { Average number of drugs } \\
\text { per encounter }\end{array}$ & 2.82 & $\leq 3$ \\
$\begin{array}{l}\text { Percentage of encounters } \\
\text { with antibiotics }\end{array}$ & 13.3 & $\leq 30$ \\
$\begin{array}{l}\text { Percentage of encounters } \\
\text { with an injection }\end{array}$ & 7.6 & $\leq 10$ \\
$\begin{array}{l}\text { Percentage of drugs } \\
\text { prescribed by generic name }\end{array}$ & 80.1 & 100 \\
$\begin{array}{l}\text { Percentage of drugs } \\
\text { prescribed from the }\end{array}$ & 40.4 & 100 \\
essential drug list & & \\
\hline $\begin{array}{l}\text { WH0: World Health Organization } \\
\text { Pen }\end{array}$ & &
\end{tabular}

Table 3: Antibiotics prescribed for patients at Family Medicine and Community Health Clinic in Sultan Qaboos University Hospital

\begin{tabular}{ll}
\hline Antibiotics & Frequency (\%) \\
\hline Amoxicillin/Clavulanic acid & $16(31)$ \\
Sodium fusidate 2\% & $13(25.5)$ \\
Azithromycin & $6(11.8)$ \\
Mupirocin 2\% & $5(9.8)$ \\
Amoxicillin & $2(3.9)$ \\
Tetracycline & $2(3.9)$ \\
Flucloxacillin & $2(3.9)$ \\
Silver sulfadiazine & $1(2)$ \\
Ofloxacin & $1(2)$ \\
Nitrofurantoin & $1(2)$ \\
Tobramycin/Dexamethasone & $1(2)$ \\
Cefuroxime & $1(2)$ \\
Total & $51(100)$ \\
\hline
\end{tabular}

Data analysis

Data were analyzed using the software Statistical Package for the Social Sciences version 23.0 (SPSS ${ }^{\mathrm{TM}}$, Chicago, IL, USA). Descriptive analysis was used for continuous data using mean \pm standard deviation and for categorical data using actual numbers and percentages to present the data.

\section{RESULTS}

A total of 300 patients (mean age of $38.16 \pm 18.45$ ) with 892 prescriptions were assessed during the study period. Female patients were relatively more than males (55.7\% and $44.3 \%$, respectively). Elderly patients accounted for $2.7 \%$ of the cases $(n=20)$

A total of 892 prescriptions (151 drugs) were assessed in the study with an average of $2.82 \pm 0.163$ drugs per patient. Fifty-three patients $(17.7 \%)$ were not prescribed any drugs, while 51 patients $(17.0 \%)$ were prescribed five or more drugs. The most frequently prescribed medications are shown in Table 1. According to the therapeutic class in the Anatomical Therapeutic Chemical classification system of drugs, drugs for diabetes were the most commonly prescribed class of drugs $(9.0 \%)$ followed by analgesics $(8.1 \%)$, dermatological preparations (7.1\%), and lipid-modifying agents (5.2\%). The summary of the WHO core prescribing indicators is shown in Table 2.

Forty patients (13.3\%) were prescribed a total of 51 antibiotics. The most commonly prescribed antibiotics were amoxicillin/clavulanic acid, sodium fusidate, and azithromycin (31.4\%, 25.5\%, and $11.8 \%$, respectively) among all antibiotics prescribed (Table 3 ).

The most common drugs prescribed by injection were insulin glargine, insulin aspart, and diclofenac $(34.4 \%, 25.0 \%$, and $9.4 \%$, respectively). The most common route of injection was the subcutaneous route $(77.4 \%)$.

\section{DISCUSSION}

Evaluation of the drug prescribing pattern in the Family Medicine and Community Health Clinic at Sultan Qaboos University Hospital showed that most of the WHO prescribing indicators were within the optimal values set by the WHO (Table 2). A comparison between our data and the WHO geographic regions is shown in Table 4. By looking into the Eastern Mediterranean region, to which Oman belongs, our data show that the Family Medicine and Community Health Clinic has three better prescribing indicators (percentage of encounters with antibiotics, percentage of encounters with an injection, and percentage of drugs prescribed by generic name) compared to the regional data. However, one indicator (percentage of drugs prescribed from the EDL) has lower value in our study compared to the Eastern Mediterranean region.

The average number of drugs per encounter in our study (2.82) was within the optimal range $(\leq 3)$. It was similar to the Eastern Mediterranean region data (2.7) and also to other individual studies done in the region such as Kuwait (2.9), Jordan (2.93), and Pakistan

Table 4: Comparison of the WHO core prescribing indicators between the study and the WHO geographic regions [14]

\begin{tabular}{|c|c|c|c|c|c|c|c|}
\hline \multirow[t]{2}{*}{ Prescribing indicator } & \multirow[t]{2}{*}{ Our study } & \multicolumn{6}{|c|}{ WHO geographic region* } \\
\hline & & Latin America & Europe & Africa & Eastern Mediterranean & South East Asia & West Pacific \\
\hline $\begin{array}{l}\text { Average number of drugs per } \\
\text { encounter }\end{array}$ & 2.82 & 1.9 & 2.1 & 2.6 & 2.7 & 2.4 & 2.8 \\
\hline $\begin{array}{l}\text { Percentage of encounters with } \\
\text { antibiotics }\end{array}$ & 13.3 & 37 & 40.9 & 45.9 & 53.6 & 47.9 & 50.8 \\
\hline $\begin{array}{l}\text { Percentage of encounters with } \\
\text { an injection }\end{array}$ & 7.6 & 13.2 & 18.7 & 28.4 & 27.1 & 9.7 & 27.1 \\
\hline $\begin{array}{l}\text { Percentage of drugs prescribed } \\
\text { by generic name }\end{array}$ & 80.1 & 67.3 & 38.3 & 65.1 & 57.1 & 44.7 & 66.5 \\
\hline $\begin{array}{l}\text { Percentage of drugs prescribed } \\
\text { from the essential drug list }\end{array}$ & 40.4 & 71.4 & 59 & 89 & 90.8 & 77 & 75.5 \\
\hline
\end{tabular}


(2.83) $[4,7,8]$. This indicator gives an idea about polypharmacy in a health-care setting which has implications on drug's adverse effects, drug interactions, and patient's compliance. Reports from different parts of the world yield different values for this indicator because it is affected by the availability of clinical guidelines, disease burden, marketing pressure, patients' demographics, cultural beliefs, and physician's competency [9].

Antibiotics were prescribed in $13.3 \%$ of the encounters, which is within the WHO optimal level $(\leq 30 \%)$. This was lower than all other WHO geographic regions shown in Table 4 . This might reflect the awareness of prescribing doctors about rational antibiotic prescribing and also the nature of presenting conditions to the clinic. Other studies done in the region showed a higher level of antibiotic prescribing (39.1\%, $52.1 \%$, and $51.5 \%$ in Kuwait, Iran, and Pakistan, respectively) $[4,7,9]$. It is well documented that irrational use of antibiotics might lead to the development of antibiotic resistance resulting in more hospital admissions due to infections and thus increasing the cost of management.

The percentage of encounters with an injection in our study was $7.6 \%$, and this is within the optimal WHO value $(\leq 10 \%)$. The injectable drugs in our study were mainly insulin preparations, and this might reflect the burden of diabetes in our population. The percentage of encounters with an injection in our study was close to the South East Asia region data and lower than all other regions. The studies from Egypt, Jordan, and Kuwait showed 9.9\%, 8.1\%, and 9.1\% encounters with injections, respectively $[7,8,10]$. In general, excessive use of injections is not recommended as it increases the risk of acquiring infections such as hepatitis B and HIV, the cost of injectable drugs is higher than the oral formulation, and it requires supervision by skilled health-care personnel.

Only $80.1 \%$ of the drugs were prescribed by generic name which is lower than the $100 \%$ optimal level set by the WHO. In fact, none of the WHO geographical regions reached the $100 \%$ optimal level (Table 4 ). The Eastern Mediterranean region was lower than our value (57.1\%). In contrast, a study conducted in India showed that the majority of drugs $(92.07 \%)$ were prescribed by the brand name [11]. Drugs prescribed by brand name in our setting were mainly those which contain drug combinations and dermatological preparations. In general, the Family Medicine and Community Health Clinic utilizes an electronic prescribing system in which almost all of the drugs are registered as generic name. Although the WHO recommends prescribing generic drugs for the sake of safety and better communication between health-care providers, there are several factors that affect the prescribing of generic drugs including physician's beliefs, pharmaceutical companies pressure, and the lack of guidelines and policy for implementation of generic prescribing [9].

The WHO EDL contains a list of well-established drugs with clear clinical use and lower cost than newer drugs [12]. Our data revealed that only $40.4 \%$ of drugs were prescribed from the WHO EDL. This is lower than the optimal WHO value $(100 \%)$ and lower than all other WHO geographic regions (Table 4). This could be explained partly that the Family Medicine and Community Health Clinic is a university health center which provides branded medications for most of the conditions. Possibly, a higher value would be obtained from the setting of health centers in the general community. Low EDL prescribing in other studies was attributed to several factors, including the lack of enforcement, inadequate distribution of EDL, the influence of drug representatives, and inadequate sensitization among health workers [13].

\section{CONCLUSION}

Our data showed that most of the WHO core prescribing indicators in the Family Medicine and Community Health Clinic were within the optimal range. These indicators are used as a benchmark for rational drug prescribing and as objective measures to describe drug use patterns in health-care facilities of the country thus enabling policy-makers to monitor the quality of drug prescribing and develop clinical practice guidelines for rational drug prescribing.

\section{AUTHORS' CONTRIBUTIONS}

Al-Rubkhi SS: Write-up of proposal, collection of data. Al-Hinai M: Write-up of manuscript, providing access to patients, revising the data. Al-Ghafri F: Collection and analysis of data, revising the manuscript. Al Balushi KA (corresponding author): Preparing and revising the manuscript, overall supervision of the work.

\section{CONFLICTS OF INTEREST}

The authors declare that they have no conflicts of interest.

\section{REFERENCES}

1. World Health Organization. Promoting Rational Use of Medicines: Core Components-Who Policy Perspectives on Medicines. Geneva: World Health Organization. 2002. Available from: http://www.apps.who.int/ medicinedocs/en/d/Jh3011e. [Last accessed on 2018 May].

2. World Health Organization. Medicines use in Primary Care in Developing and Transitional Countries: Facts Book Summarizing Results from Studies Reported between 1990 and 2006. Geneva, Switzerland: World Health Organization; 2009. Available from: http:// www.who.int/medicines/publications/who emp 2009.3/en. [Last accessed on 2018 May].

3. World Health Organization. The Rational use of Drugs: Report of the conference of experts, Nairobi, 25-29 November 1985. Geneva: World Health Organization; 1987. Available from: http://www.apps.who.int/ medicinedocs/documents/s17054e/s17054e.pdf. [Last accessed on 2018 May].

4. Atif M, Sarwar MR, Azeem M, Umer D, Rauf A, Rasool A, et al. Assessment of WHO/INRUD core drug use indicators in two tertiary care hospitals of Bahawalpur, Punjab, Pakistan. J Pharm Policy Pract 2016;9:27.

5. Summoro TS, Gidebo KD, Kanche ZZ, Woticha EW. Evaluation of trends of drug-prescribing patterns based on WHO prescribing indicators at outpatient departments of four hospitals in Southern Ethiopia. Drug Des Dev Ther 2015;9:4551-7.

6. Krähenbühl-Melcher A, Schlienger R, Lampert M, Haschke M, Drewe J, Krähenbühl S. Drug-related problems in hospitals: A review of the recent literature. Drug Saf 2007;30:379-407.

7. Awad A, Al-Saffar N. Evaluation of drug use practices at primary healthcare centers of Kuwait. Eur J Clin Pharmacol 2010;66:1247-55.

8. Al-Azayzih A, Al-Azzam SI, Alzoubi KH, Shawaqfeh M, Masadeh MM. Evaluation of drug-prescribing patterns based on the WHO prescribing indicators at outpatient clinics of five hospitals in Jordan: A cross-sectional study. Int J Clin Pharmacol Ther 2017;55:425-32.

9. Ahmadi F, Zarei E. Prescribing patterns of rural family physicians: A study in Kermanshah Province, Iran. BMC Public Health 2017; 17:908-14.

10. Akl OA, El Mahalli AA, Elkahky AA, Salem AM. WHO/INRUD drug use indicators at primary healthcare centers in Alexandria, Egypt. J Taibah Univ Med Sci 2014;9:54-64.

11. Available from: http://www.who.int/medicines/publications/ essentialmedicines/EML2015_8-May-15.pdf. [Last accessed on 2018 May].

12. Naveen A, Ramesh B, Teki S. Prescription auditing in regard with the prescription patterns in a tertiary care teaching hospital. Asian J Pharm Clin Res 2018;11:176-80.

13. Ofori-Asenso R, Brhlikova P, Pollock AM. Prescribing indicators at primary health care centers within the WHO African region: A systematic analysis (1995-2015). BMC Public Health 2016;16:724-37.

14. Holloway KA, Ivanovska V, Wagner AK, Vialle-Valentin C, Ross-Degnan D. Have we improved use of medicines in developing and transitional countries and do we know how to? Two decades of evidence. Trop Med Int Health 2013;18:656-64. 